\title{
Predicting Response to PEEP in Mechanically Ventilated Pediatric Patients: What Are the Odds?
}

Critically ill neonatal and pediatric patients are commonly supported with conventional mechanical ventilation. The provision of safe and effective mechanical ventilation is a crucial skill for pediatric intensivists, especially as ventilator management continues to evolve. The past 20 years have seen dramatic changes in lung-protective mechanical ventilation since the publication of the sentinel investigation demonstrating that lower tidal volumes and limitation of inspiratory pressure improved outcomes in adults with ARDS. ${ }^{1}$ Despite limited pediatric data with no randomized controlled trials detailing the ideal ventilator strategy for neonates and children, the Pediatric Acute Lung Injury Consensus Conference (PALICC) recommendations ${ }^{2}$ were recently published and align with the adult data as they endorse lower tidal volumes $(3-6 \mathrm{~mL} / \mathrm{kg}$ ) for patients with poor respiratory system compliance, inspiratory plateau pressures $<28 \mathrm{~cm} \mathrm{H}_{2} \mathrm{O}$, and permissive hypercapnia. In addition to minimizing volutrauma and barotrauma, the use of an open lung strategy with PEEP titration to minimize lung collapse and atelectrauma has become routine. The PALICC guidelines embrace this concept as they recommend PEEP up to $15 \mathrm{~cm} \mathrm{H}_{2} \mathrm{O}$ or greater for severe pediatric ARDS. ${ }^{2,3}$ As pediatric mechanical ventilation continues to be refined in the era of open lung ventilation, it is increasingly important for providers to understand and predict how individual patients will respond to the PEEP titrations we implement at the bedside.

In the current issue of Respiratory CARE, Smallwood et $\mathrm{al}^{4}$ present data from an academic pediatric ICU demonstrating the clinical effects of PEEP manipulation. The investigators aimed to quantify the probability that a patient will have a response to changes in PEEP and to determine the clinical factors associated with this response. In this investigation, a positive response was defined as a subject who had an increase in either oxygenation $\left(\mathrm{S}_{\mathrm{pO}_{2}} / \mathrm{F}_{\mathrm{IO}_{2}}\right)$, dynamic respiratory system compliance $\left(\mathrm{C}_{\mathrm{RS}}\right)$, or dead-space fraction $\left(\mathrm{V}_{\mathrm{D}} / \mathrm{V}_{\mathrm{T}}\right)$ after a PEEP in-

Correspondence: David A Turner MD, Division of Pediatric Critical Care Medicine, Department of Pediatrics, Duke Children's Hospital, 2301 Erwin Rd, Durham, NC 27710. E-mail: david.turner@duke.edu.

DOI: $10.4187 /$ respcare.07371 crease. An acceptable or favorable response when decreasing PEEP was similarly defined as maintaining or improving in at least one of these 3 parameters. The investigation consisted of a retrospective review of 76 subjects admitted

See the Original Study on Page 1193

to their pediatric ICU who were $<18$ y old, received conventional mechanical ventilation for $>24 \mathrm{~h}$, and had hypoxic respiratory failure (defined as an oxygen saturation index $>5$ ). These data demonstrate that just over half $(56 \%)$ of cases had an improvement in oxygenation following routine increases in PEEP. Those who responded favorably to this increase in PEEP had worse lung injury prior to the change, as demonstrated by higher $\mathrm{F}_{\mathrm{IO}_{2}}$ requirements, mean airway pressures, and oxygen saturation indices. Only $47 \%$ of subjects responded favorably to a decrease in PEEP, with favorable response associated with a lower $\mathrm{V}_{\mathrm{D}} / \mathrm{V}_{\mathrm{T}}$ prior to intervention.

This investigation outlines the considerable challenges that exist in clinical decision-making surrounding PEEP titration. As discussed by the authors and outlined in the PALICC guidelines, PEEP is important for oxygenation in mechanically ventilated patients. ${ }^{2,5,6}$ However, on the basis of this investigation, the authors challenge the general paradigm that increasing PEEP improves oxygenation because they found that the probability of increased oxygenation with increased PEEP was "not much better than the flip of a coin." 4 Even though only $56 \%$ of the subjects had a positive response to increasing PEEP, it is important to note that those subjects with the most severe lung injury were the cohort with the best response. Similarly, subjects with indicators of less severe or improving lung injury were those with a favorable response to decreases in PEEP. Prospectively identifying those patients most likely to benefit from PEEP changes by assessing invasive and noninvasive parameters is a crucial consideration as PEEP adjustment is considered. Other factors affecting clinical decision-making surrounding PEEP titration addressed by the authors include the potential impact of both recruitment maneuvers in conjunction with increases in PEEP and the time needed to assess the full clinical response to the implemented change. Recruitment maneuvers in conjunction with stepwise PEEP titration have demon- 


\section{EDITORIALS}

strated an increase in oxygenation in adults and children with ARDS, although controversy exists on which approach to lung recruitment is best. ${ }^{7-9}$ Because this study was conducted retrospectively, the authors were unable to include or comment on whether recruitment maneuvers in addition to a simple increase in PEEP were associated with improved responsiveness to PEEP titration. Previous investigations have suggested that only 5-20 min are needed to assess the impact of PEEP titration on oxygenation in adults, ${ }^{10-12}$ although previous work by the authors indicated that it can take as long as $70 \mathrm{~min}$ in children for the impact to be fully realized. ${ }^{13}$ These data suggest that it is reasonable to wait up to one hour to assess oxygenation when considering the impact of PEEP titration.

Although oxygenation is important in the management of mechanically ventilated patients with ARDS, it is important to note that interventions to enhance oxygenation alone in many circumstances have not been associated with improved mortality. For example, while inhaled nitric oxide transiently increases oxygenation in adults and children with ARDS, no reduction in mortality was demonstrated. ${ }^{14}$ Similarly, in pediatric ARDS, prone positioning has been reported to improve oxygenation, but no improvement in ventilator-free days or mortality were seen. ${ }^{15}$

Fortunately, the potential benefits of PEEP extend beyond improvements in oxygenation. In their investigation, Smallwood et $\mathrm{al}^{4}$ documented an improvement in dynamic respiratory system compliance and deadspace fraction in their definition of a favorable response to an increase in PEEP. Increasing PEEP can maintain the functional residual capacity above the closing capacity of the lung and thereby prevent atelectrauma. This improved compliance may lead to reduced barotrauma through the use of lower driving pressures to ventilate these patients. Khemani et al ${ }^{16}$ recently demonstrated that pediatric subjects with ARDS who were managed with lower PEEP relative to $\mathrm{F}_{\mathrm{IO}_{2}}$ than ARDSNet recommendations had higher mortality. Adult data also indicate that PEEP titrations can decrease the relative risk of death in ARDS secondary to improved lung mechanics and subsequent decreased driving pressures. ${ }^{17}$

It is possible that in the current investigation, stratification of patients by degree of lung injury may have improved the rate of favorable responses from both increases and decreases in PEEP. Although this investigation was not designed to stratify patients in this manner, the data suggest that the likelihood of response to PEEP may depend most upon degree of lung injury. The authors should be applauded for this creative study design, which helps fill the knowledge gap surrounding our ability to predict the impact of PEEP titration in critically ill children. This study highlights the importance of assessing a wide range of clinical parameters both before and after
PEEP titration. Additional investigations of this nature are needed to guide clinicians at the bedside as we work to refine our approach to mechanical ventilation to improve outcomes for critically ill children.

Tobias L Straube Kyle J Rehder

David A Turner

Division of Pediatric Critical Care Medicine

Department of Pediatrics

Duke Children's Hospital

Durham, North Carolina

\section{REFERENCES}

1. Acute Respiratory Distress Syndrome Network, Brower RG, Matthay MA, Morris A, Schoenfeld D, Thompson BT, Wheeler A. Ventilation with lower tidal volumes as compared with traditional tidal volumes for acute lung injury and the acute respiratory distress syndrome. N Engl J Med 2000;342(18):1301-1308.

2. Pediatric Acute Lung Injury Consensus Conference Group. Pediatric acute respiratory distress syndrome: consensus recommendations from the Pediatric Acute Lung Injury Consensus Conference. Pediatr Crit Care Med 2015;16(5):428-439.

3. Rimensberger PC, Cheifetz IM, Pediatric Acute Lung Injury Consensus Conference Group. Ventilatory support in children with pediatric acute respiratory distress syndrome: proceedings from the Pediatric Acute Lung Injury Consensus Conference. Pediatr Crit Care Med 2015;16(5 Suppl 1):S51-S60.

4. Smallwood CD, Walsh BK, Arnold JH, Gouldstone A. Empirical probability of positive response to PEEP changes and mechanical ventilation factors associated with improved oxygenation during pediatric ventilation. Respir Care 2019;64(10):1193-1198.

5. Tyler DC. Positive end-expiratory pressure: a review. Crit Care Med 1983;11(4):300-308.

6. Weisman IM, Rinaldo JE, Rogers RM. Current concepts: positive end-expiratory pressure in adult respiratory failure. N Engl J Med 1982;307(22):1381-1384.

7. Cruces P, Donoso A, Valenzuela J, Diaz F. Respiratory and hemodynamic effects of a stepwise lung recruitment maneuver in pediatric ARDS: a feasibility study. Pediatr Pulmonol 2013;48(11):1135-1143.

8. Hess DR. Recruitment maneuvers and PEEP titration. Respir Care 2015;60(11):1688-1704.

9. Povoa P, Almeida E, Fernandes A, Mealha R, Moreira P, Sabino H. Evaluation of a recruitment maneuver with positive inspiratory pressure and high PEEP in patients with severe ARDS. Acta Anaesthesiol Scand 2004;48(3):287-293.

10. Brower RG. Time to reach a new equilibrium after changes in PEEP in acute respiratory distress syndrome patients. Intensive Care Med 2013;39(11):2053-2055.

11. Chiumello D, Coppola S, Froio S, Mietto C, Brazzi L, Carlesso E, et al. Time to reach a new steady state after changes of positive end expiratory pressure. Intensive Care Med 2013;39(8):1377-1385.

12. Tugrul S, Cakar N, Akinci O, Ozcan PE, Disci R, Esen F, et al. Time required for equilibration of arterial oxygen pressure after setting optimal positive end-expiratory pressure in acute respiratory distress syndrome. Crit Care Med 2005;33(5):995-1000.

13. Smallwood CD, Walsh BK, Arnold JH, Gouldstone A. Equilibration time required for respiratory system compliance and oxygenation response following changes in positive end-expiratory pres- 


\section{EDITORIALS}

sure in mechanically ventilated children. Crit Care Med 2018; 46(5):e375-e379.

14. Gebistorf F, Karam O, Wetterslev J, Afshari A. Inhaled nitric oxide for acute respiratory distress syndrome (ARDS) in children and adults. Cochrane Database Syst Rev 2016;(6):CD002787.

15. Curley MA, Hibberd PL, Fineman LD, Wypij D, Shih MC, Thompson JE, et al. Effect of prone positioning on clinical outcomes in children with acute lung injury: a randomized controlled trial. JAMA 2005;294(2):229-237.
16. Khemani RG, Parvathaneni K, Yehya N, Bhalla AK, Thomas NJ, Newth CJL. Positive end-expiratory pressure lower than the ARDSNetwork protocol is associated with higher pediatric acute respiratory distress syndrome mortality. Am J Respir Crit Care Med 2018; 198(1):77-89.

17. Amato MB, Meade MO, Slutsky AS, Brochard L, Costa EL, Schoenfeld DA, et al. Driving pressure and survival in the acute respiratory distress syndrome. N Engl J Med 2015;372(8):747-755. 